\title{
Влияние атмосферы отжига на люминесцентные характеристики CVD-ZnSe
}

\author{
(C) В.П. Калинушкин ${ }^{1}$, А.А. Гладилин ${ }^{1}$, О.В. Уваров ${ }^{1}$, С.А. Миронов ${ }^{1,}$, В.А. Чапнин ${ }^{1}$, М.И. Студеникин ${ }^{1}$, \\ Н.Н. Ильичев ${ }^{1}$, Е.М. Гаврищук ${ }^{2}$, С.А. Родин ${ }^{2}$, Н.А. Тимофеева ${ }^{2}$ \\ ${ }^{1}$ Институт общей физики им. А.М. Прохорова Российской академии наук, \\ 119991 Москва, Россия \\ ${ }^{2}$ Институт химии высокочистых веществ им. Г.Г. Девятых Российской академии наук, \\ 603951 Нижний Новгород, Россия \\ ๑ E-mail: serge2016@yandex.ru
}

Поступила в Редакцию 20 августа 2021 г.

В окончательной редакции 27 августа 2021 г.

Принята к публикации 27 августа 2021 г.

\begin{abstract}
Исследуется влияние атмосферы отжигов CVD-ZnSe, проводимых в режимах, близких к процедуре их легирования железом, на люминесцентные характеристики этих кристаллов. Обнаружено, что отжиги в атмосфере аргона и селена приводят к качественному изменению примесно-дефектного состава и к сложному пространственному распределению люминесцентных характеристик CVD-ZnSe, особенно в области кристалла на расстоянии до 400 мкм от поверхности. В случае отжига цинка его люминесцентные характеристики более однородны, за исключением приповерхностной зоны шириной $\sim 100$ мкм, имеющей высокую интенсивность люминесценции во всем исследуемом спектральном диапазоне (0.44-0.72 мкм). Полученные результаты интерпретируются на основе предположения об испарении цинка при отжиге в аргоне и селене. На основе анализа пространственного распределения люминесценции делаются предположения о природе наблюдаемых примесно-дефектных центров.
\end{abstract}

Ключевые слова: двухфотонная конфокальная микроскопия, CVD-ZnSe, примесно-дефектный состав, высокотемпературный отжиг.

DOI: $10.21883 /$ FTP.2022.01.51817.9731

\section{1. Введение}

Легированный железом и хромом $\mathrm{ZnSe}$ активно используется для создания лазеров ИК-диапазона [1-3]. При этом изучается возможность создания лазерных систем, в которых инверсная населенность ионов железа и хрома создается не с помощью оптической накачки, а ударной ионизацией горячими электронами $[4,5]$. Эти работы требуют детального исследования примеснодефектного состава используемых для этих целей кристаллов и влияния на него различных технологических операций и отжигов. Во многих случаях создание лазерных кристаллов осуществляется методом высокотемпературного $\left(900-1250^{\circ} \mathrm{C}\right)$ диффузионного легирования селенида цинка ионами железа и хрома. В качестве основы используется поликристаллический $\mathrm{ZnSe}$, синтезированный в процессе химического осаждения из газовой фазы (chemical vapor deposition - CVD), или CVD-ZnSe [1-3,5-8]. В этих случаях вместе с диффузией происходит и отжиг кристаллов. [6-8]. В связи с вышесказанным представляет интерес исследование влияния отжигов в различных атмосферах (Ar, Se, Zn) в режимах, близких к процессу легирования железом, на примесно-дефектный состав в поликристаллическом $\mathrm{CVD}-\mathrm{ZnSe}$. В данной работе исследуется влияние отжига на пространственное распределение люминесценции в диапазоне 0.44-0.72 мкм. В качестве метода исследования будет использоваться двухфотонная конфокальная микроскопия (ДФКМ), которая позволяет изучать пространственное распределение люминесценции по всему объему кристалла толщиной до 3 мм с разрешением в несколько мкм. Хотя исследованию влияния отжигов на люминесценцию $\mathrm{ZnSe}$ посвящено много работ [9-12], такого рода эксперименты, по имеющейся у нас информации, проводятся впервые.

\section{2. Схема эксперимента}

В работе исследовали исходный и отожженный при температуре $1000^{\circ} \mathrm{C}$ поликристаллический CVD-ZnSe, полученный в результате реакции паров цинка и селеноводорода в токе аргона. Образцы в форме параллелепипедов размерами $8 \times 6 \times 4$ мм вырезали из части пластины с однородной микроструктурой. Пропускание материала в спектральном диапазоне 2-14 мкм составляло $\sim 70 \%$. Для отжига заготовки помещали в кварцевые ампулы, которые подсоединялись к форвакуумному насосу и к источнику аргона. Осуществлялось пятикратное промывание ампул аргоном, что позволяло снизить концентрацию примесей, обусловленных атмосферой $\left(\mathrm{N}_{2}\right.$, $\left.\mathrm{O}_{2}, \mathrm{CO}_{2}, \mathrm{H}_{2} \mathrm{O}\right)$. Далее в ампулу напускался Ar таким образом, чтобы его давление при заданной температуре отжига составляло $\sim 1$ атм, затем ампулы запаивали. Для проведения эксперимента в парах матричных компонентов использовали ампулы с перетяжкой. В одной части ампулы находились исследуемые образцы, а в 
другой — навески Zn или Se. Путем расчета подбиралась такая масса навески, чтобы при температуре термического отжига давление паров матричного компонента составляло $\sim 1$ атм. Размещение образцов CVD-ZnSe оставляло открытыми все поверхности образца. Отжиги проводили в лабораторном термостате СНОЛ 6/12 при температуре $1000^{\circ} \mathrm{C}$ в течение 72 ч. Охлаждение ампул с образцами проходило в режиме выключенного термостата. Затем ампулы вскрывали, образцы извлекали и подвергали механическому полированию. Исследование люминесцентных характеристик проводилось с помощью двухфотонной конфокальной микроскопии. В данной работе использовался конфокальный микроскоп фирмы Carl Zeiss LSM 710 NLO. Двухфотонное возбуждение осуществлялось лазером с перестраиваемой длиной волны в диапазоне 0.71-1.05 мкм (в данной работе использовалось излучение с длиной волны 0.8 мкм). Длительность импульса составляла 150 фс, частота 80 МГц, максимальная средняя мощность $0.1-1$ Вт варьировалась в зависимости от условий детектирования и оптимизировалась для получения контрастного изображения люминесценции образца. Спектры люминесценции регистрировались в диапазоне $440-725$ нм со спектральным разрешением 10 нм. Эти параметры хорошо подходят для исследования кристаллического $\mathrm{ZnSe}$, ширина запрещенной зоны которого составляет при комнатной температуре $\sim 2.7$ эВ. Таким образом, на этом приборе возможна эффективная реализация двухфотонного возбуждения и регистрация краевой и части дефектно-примесной люминесценции (в диапазоне 460-715 нм). Имеющееся экспериментальное оборудование позволяло регистрировать и обрабатывать трехмерные картины распределения краевой и дефектнопримесной люминесценции исходных и легированных железом кристаллов $\mathrm{ZnSe}$ на глубину до 3 мм с пространственным разрешением порядка нескольких микрометров. Время снятия одной объемной „карты“ на глубину 1 мм с шагом 25 мкм и размером ,плоской“ карты $1 \times 1$ мм составляло $\sim 5$ мин. Все эксперименты проводились при комнатной температуре. Подробно эта методика описана в $[13,14]$.

\section{3. Экспериментальные результаты}

В работе исследуется влияние на пространственное распределение люминесцентных характеристик CVD-ZnSe отжигов в указанных выше режимах. На pис. 1 приведены плоские карты исходного CVD-ZnSe, снятые на глубине 100 мкм на длинах волн люминесценции 473 нм (рис. $1, a), 520$ и 473 нм (рис. $1, b$ ), и 715 нм (рис. 1,c), и спектры люминесценции различных областей кристаллов. Эти карты были типичны для всех исследуемых в данной работе образцов исходного CVD-ZnSe. Люминесцентные характеристики этих кристаллов в макроскопическом плане были достаточно однородны. На приведенных картах хорошо выявляется зернистая структура кристаллов. Размеры зерен были порядка нескольких десятков микрометров. Интенсивность люминесценции внутри зерен существенно различалась. Границы зерен обычно характеризовались низкой интенсивностью люминесценции (рис. 1, $a$ и $b$ ). Однако в отдельных областях границ зерен наблюдаются ярко светящиеся в примеснодефектном диапазоне люминесценции точки размерами в несколько микрон (рис. $1, b$ ). На рис. $1, a$ и $b$ приведены спектры люминесценции различных областей размерами в несколько десятков микрометров и ярко светящихся точек. Эти результаты были типичны для исходного CVD-ZnSe. Видно, что в большей части кристалла в спектрах доминирует линия излучения с длиной волны $463-473$ нм (рис. 1, $a$, кривые $1-3$ ), которая в работах $[9,15]$ ассоциировалась с излучением экситона. Регистрируется также слабая по интенсивности люминесценция примесно-дефектных центров (ПДЦ) - линия с максимумом интенсивности вблизи 520 нм с широким длинноволновым хвостом до 600 нм и еще более слабые (на грани чувствительности аппаратуры) по интенсивности линии красной люминесценции от 650 до 725 нм (см. вставку на рис. $1, a$, кривые $1-3$ ). В яркой точке доминирует люминесценция с максимумом вблизи 520 нм и длинноволновым хвостом до 580 нм (в дальнейшем линия 520). Линия излучения экситона также регистрируется, но она несколько слабее по интенсивности, чем линия 520 (рис. $1, b$, кривые 1-3). С большой долей уверенности можно предполагать, что наблюдаемое при „интегральных“ измерениях излучение ПДЦ в основном состоит из линии 520, которая слилась с более слабым излучением другими ПДЦ вблизи 540-600 нм. Эта часть спектра люминесценции может быть результатом сложения нескольких линий. Также на рис. $1, c$ видно, что красная люминесценция распределена по кристаллу достаточно однородно и выглядит как люминесценция мелких точек.

На рис. 2 приведены плоские карты отожженного в аргоне CVD-ZnSe ( $\mathrm{ZnSe}-\mathrm{Ar})$, снятые на глубине 100 мкм на длинах волн люминесценции 473 (рис. 2,a), 512 и 715 нм (рис. 2, b), и 570 нм (рис. 2,c). В выделенной на плоской карте области зарегистрированы зависимости интенсивности люминесценции на длинах волн 473 , 512,570 и 715 нм (рис. 2, b). На рис. 2, $a$ приведены спектры люминесценции из разных областей образца. Из этих рисунков видно, что образец можно разделить минимум на две области - область 1 , прилегающая к поверхности, шириной $\sim 300$ мкм, в которой минимизированы люминесценция экситона и ПДЦ в диапазоне до 520 нм, и область 2, внутри образца. Область 1 имеет вид широкой полосы, параллельной поверхности. Она состоит из двух подзон. В первой, шириной 200 мкм, примыкающей к поверхности, спектр состоит из линии люминесценции экситона слабой интенсивности и люминесценции ПДЦ в диапазоне от 520 до 620 нм с максимумом вблизи 560 нм (полоса 560), а также люминесценции красных линий (рис. 2, $a, c$, кривая 1 , 

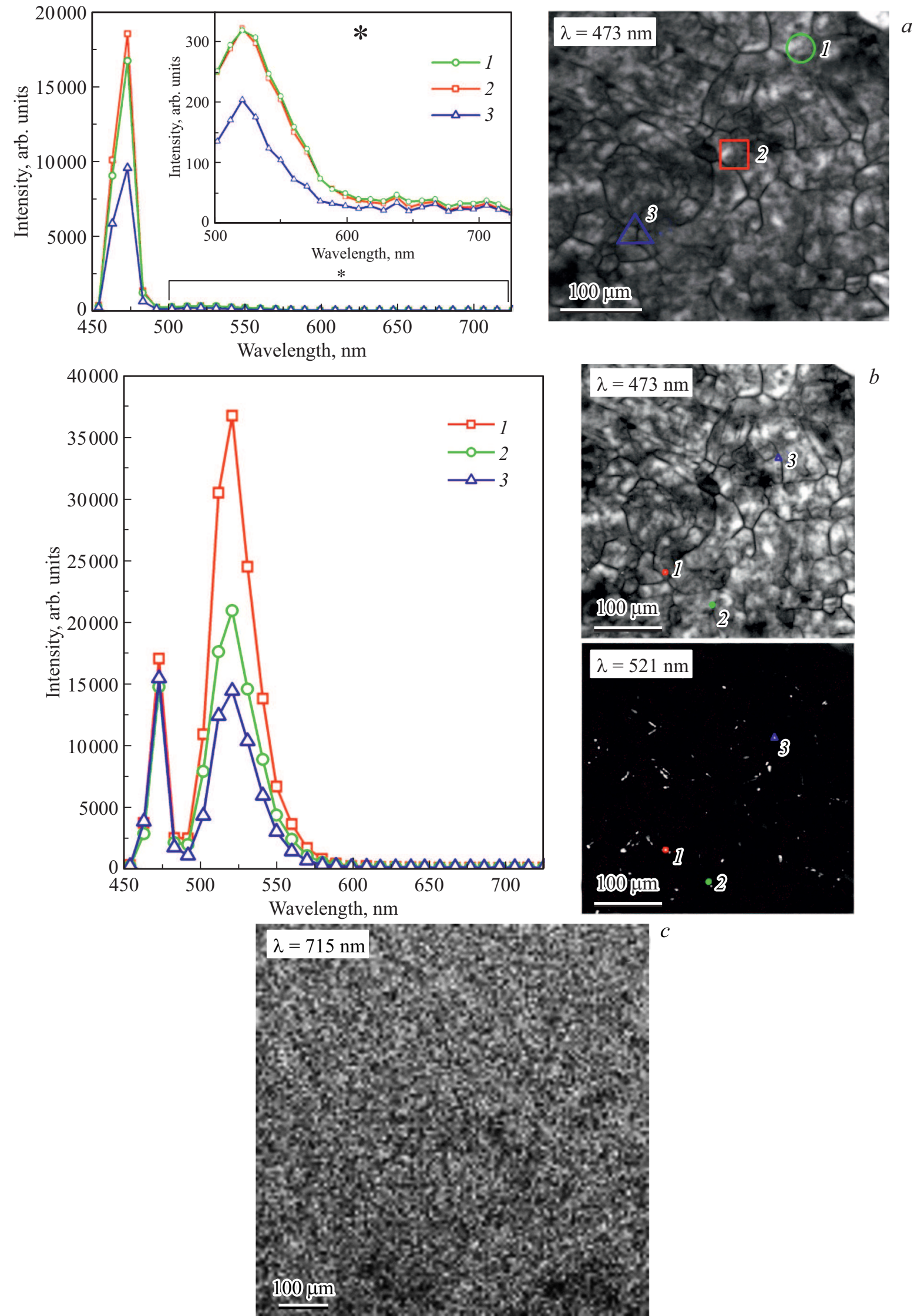

Рис. 1. $a$ - карта люминесценции исходного ZnSe на длине волны 473 нм и спектры люминесценции из выделенных на карте областей; $b$ - карты люминесценции исходного ZnSe на длинах волн 473 и 520 нм и спектры люминесценции выделенных на картах „ярких“ точек; $c$ - карта люминесценции исходного ZnSe на длине волны 715 нм. 

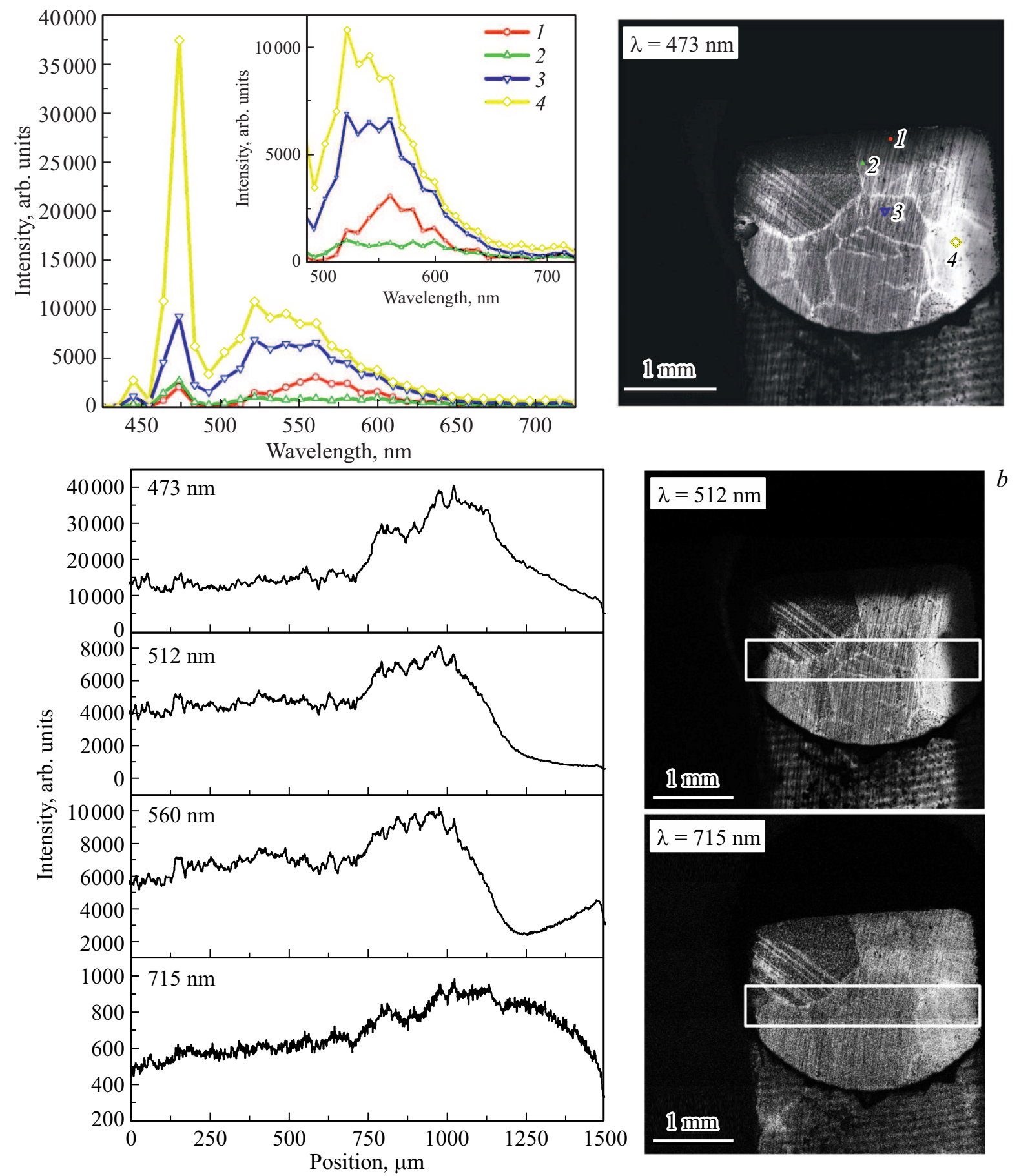

Рис. 2. $a$ - карта люминесценции $\mathrm{ZnSe}-\mathrm{Ar}$ на длине волны 473 нм и спектры люминесценции из выделенных на карте областей: кривая 1 - зона 1.1, кривая 2 - зона 1.2 , кривая 3 - зона 2.1, кривая 4 - зона 2.2; $b$ - карты люминесценции ZnSe-Ar на длинах волн 512 и 715 нм и зависимости интенсивности люминесценции от расстояния от края кристалла на длинах волн 473, 512, 560 и 715 нм; $c$ - карты люминесценции $\mathrm{ZnSe}-\mathrm{Ar}$ на длине волны 560 нм и спектры люминесценции из разных зон кристалла: кривая 1 - зона 1.1 , кривая 2 - зона 1.2 , кривая 3 - зона 2.1 , кривая 4 - зона 2.2 .

см. вставку, кривая 1). Другая подзона, расположенная за первой, характеризуется малой интенсивностью люминесценции ПДЦ в диапазоне от 480 до $650 \mathrm{нм.}$ В ней наблюдается относительно слабая экситонная и красная люминесценция (рис. 2,a,c, кривая 2, см. вставку, кривая 2). Эта подзона также имеет вид полосы шириной $~ 100$ мкм, параллельной поверхности образца. Границы подзон 1.1 и 1.2 искривляются при пересечении с границами зерен (рис. 2, $b, c$ ). Учитывая, что диффузия по границам зерен имеет свои особенности, этот факт служит подтверждением предположения, что эти подзоны образовались в результате диффузионных процессов. 

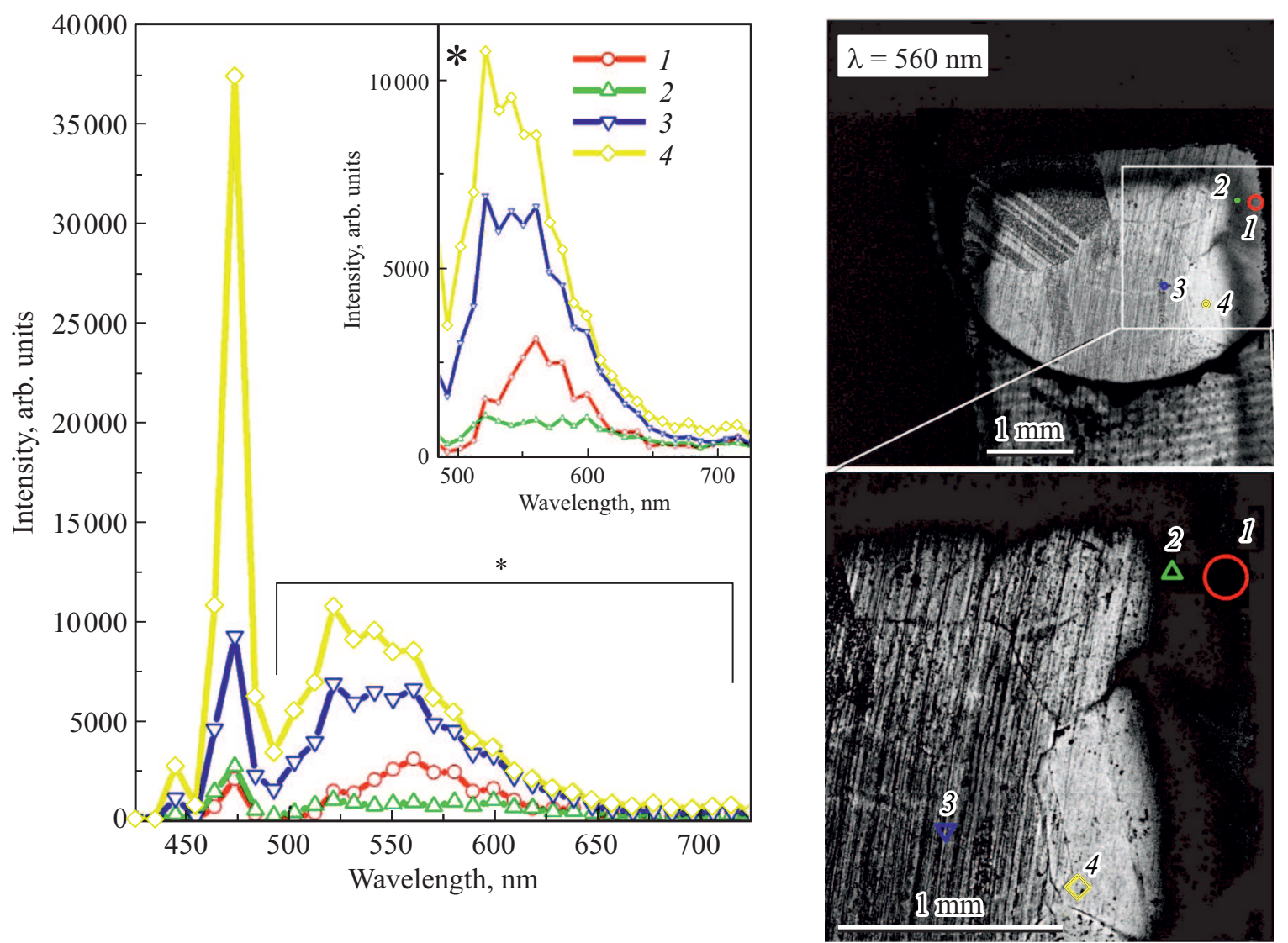

Рис. 2 (продолжение).

В области 2 в спектре доминирует люминесценция экситона и регистрируется полоса люминесценция ПДЦ с максимумом интенсивности вблизи 520, 540 и 560 нм и длинноволновым хвостом до 650 нм (полоса 520-560) и слабых красных линий с максимумами вблизи 680 и 715 нм (рис. 2, $a, b$, кривые 3,4). Скорее всего, полоса 520-560 есть результат сложения нескольких линий, в том числе полосы 560. Часть области 2, примыкающая к области 1 , шириной $\sim 400$ мкм имеет несколько более высокую интенсивность люминесценции во всем спектральном интервале (подзона 2.1), чем центральная зона кристалл - подзона it2.2 (рис. 2, a, b, кривые 3, 4). Размеры зерен существенно увеличились и составляют $>500$ мкм. В диапазоне люминесценции экситона границы зерен люминесцируют классическим образом слабая по интенсивности люминесценции узкая „темная“ сердцевина границы зерна и более сильная по интенсивности люминесценции „светлая“ область вокруг них (рис. 2,a). В части спектра 500-560 нм в области 1 и подзоне 2.1 кристалла границы зерен имеют пониженную интенсивность люминесценции, в подзоне 2.2 люминесценция границ зерен в этом диапазоне имеет аналогичный экситонной люминесценции вид (рис. 2, $b$ ). В части спектра 570-650 нм границы зерен имеют темный контраст, т. е. малую интенсивность люминесценции во всех областях кристалла (рис. 2,b). В спектральной области 670-715 нм границы зерен имеют повышенную интенсивность люминесценции во всех зонах кристалла (рис, $2, b)$. Так как образцы полировались механически, то узкая $(\sim 10$ мкм) приповерхностная зона содержит большое количество структурных дефектов. Люминесценция этой области имеет в основном слабую интенсивность во всех спектральных диапазонах. Как видно из рис. $2, b$, зависимость интенсивности люминесценции экситонов от расстояния от поверхности кристалла следующая: рост почти от нуля на границе кристалла в зоне 1 и в половине подзоны 2.1. На расстоянии $\sim 550$ мкм от поверхности образца регистрируется максимум интенсивности люминесценции. В дальнейшем наблюдается ее спад и выход на плато на расстоянии $\sim 750$ мкм от поверхности. Интенсивность плато сопоставима с интенсивностью люминесценции экситона в подзоне 1.2. Интенсивность люминесценции полосы 520-560 в зоне 1 скорее всего близка к нулю. Затем начинается ее быстрый рост, который выходит на максимум примерно там же, где максимум интенсивности люминесценции экситона. При увеличении расстояния от поверхности начинается спад интенсивности люминесценции полосы 520-560. На расстоянии $\sim 750$ мкм от поверхности кристалла она выходит на плато (рис. $2, b$ ). Таким образом, в области 2 пространственное распределение зависимости интенсивности люминесценции в 

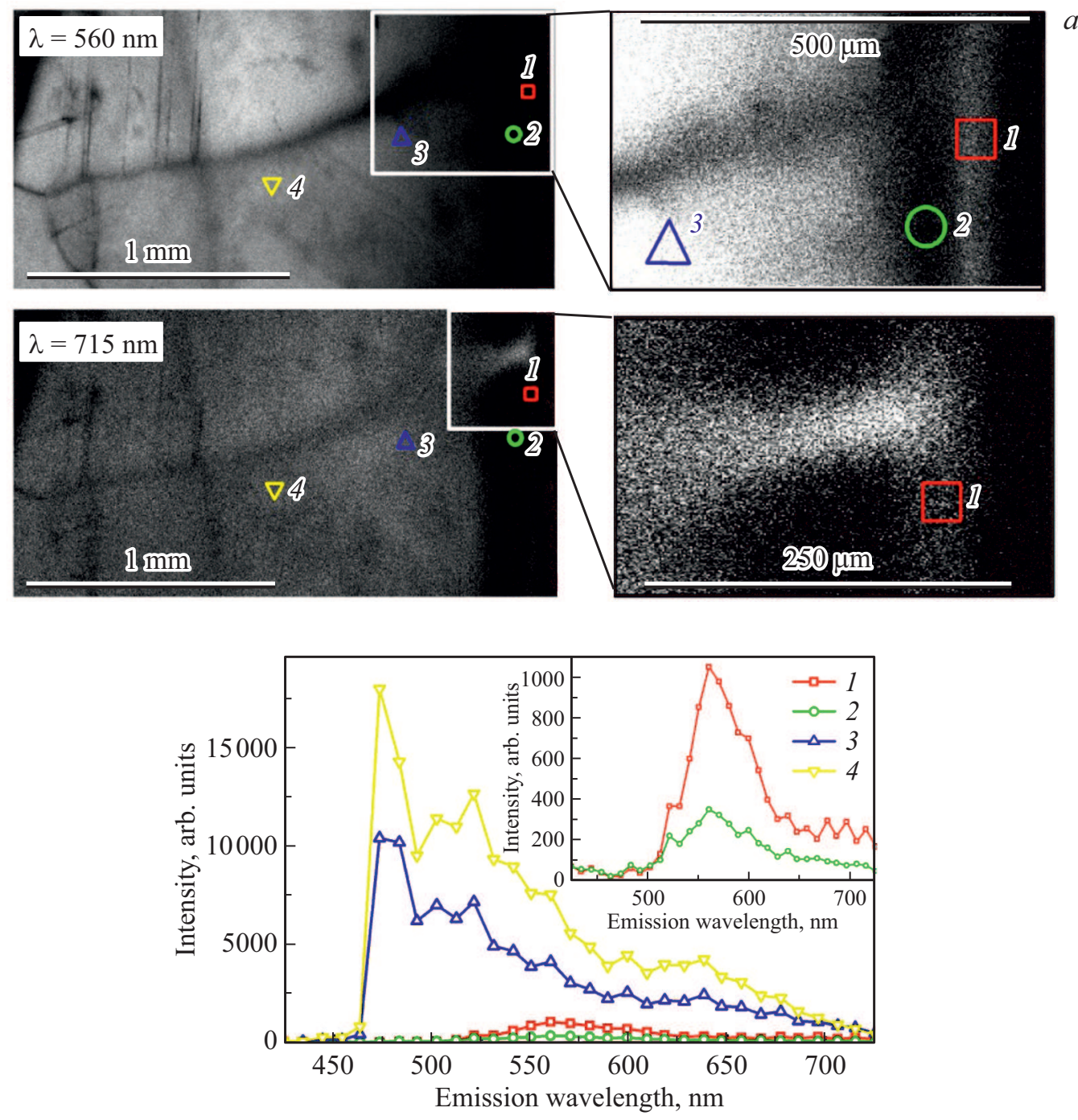

Рис. 3. $a-$ карты люминесценции $\mathrm{ZnSe}-\mathrm{Se}$ на длине волны 560 и 715 нм и спектры люминесценции из разных зон кристалла: кривая 1 - зона 1.1, кривая 2 - зона 1.2 , кривая 3 - зона 2.1, кривая 4 - зона 2.2; $b$ - карты люминесценции ZnSe-Se на длинах волн 512 и 473 нм (левая часть рисунка) и зависимости интенсивности люминесценции от расстояния от края кристалла на длинах волн 473, 512, 560 и 715 нм.

этой области спектра близко к аналогичной зависимости для экситона. Интенсивность люминесценции полосы 560 имеет максимум в подзоне 1.1, затем спад в подзоне 1.2. В этой зоне кристалла она имеет вид наблюдаемой ранее области повышенной интенсивности люминесценции (ОПИЛ) [14,16], примыкающей к краю образца. В дальнейшем она повторяет пространственное распределение интенсивности люминесценции полосы 520-560 (рис. 2, b). Не исключено, что спектры люминесценции этих ПДЦ частично совмещаются. Поэтому возможно, что пространственное распределение зависимости интенсивности люминесценции в области 2 в спектральном диапазоне определяется не полосой 560 нм. Отметим различие люминесценции границ зерен в области 2.2. Повышенная интенсивность люминесценции наблюдается в области спектра 520-560 нм, пониженная - в области спектра 570-650 нм Про- странственное распределение интенсивности люминесценции красных линий несколько иное. Первоначальный быстрый рост от нуля в зоне у поверхности шириной 100 мкм. Затем на расстоянии $\sim 400$ мкм от поверхности кристалла рост замедляется с выходом на максимум. Потом происходит медленный спад с выходом на плато на расстоянии 750-800 мкм от поверхности (рис. $2, b$ ). Как видно из рис. $2, a-c$ и из приведенных выше зависимостей интенсивности люминесценции от расстояния от поверхности образца, подзона 1.2 представляет собой полосу шириной 100 мкм, идущую параллельно поверхности кристалла с низкой интенсивностью примесной люминесценции (ОНИЛ) в спектральном диапазоне 500-650 нм, по форме похожую на ОПИЛ. При этом не исключено, что в этой области кристалла доминирует люминесценция в других спектральных диапазонах. На рис. 3 приведены плоские карты ото- 

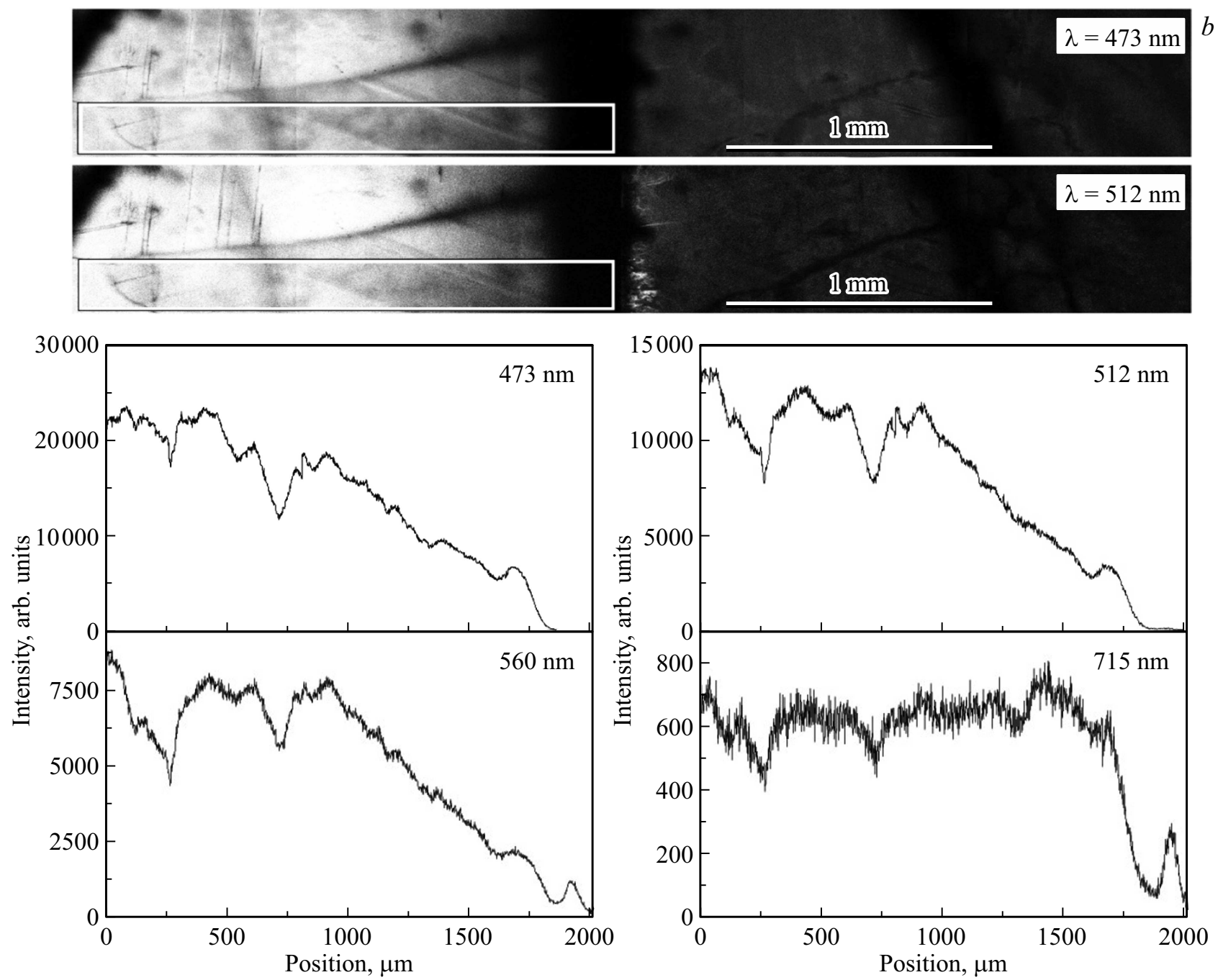

Рис. 3 (продолжение).

жженного в селене CVD-ZnSe $(\mathrm{ZnSe}-\mathrm{Se})$, снятые на глубине 100 мкм на длинах волн люминесценции 473, 512 (рис. 3, с), 570, 715 нм (рис. 3, a).

В области выделенного на плоской карте прямоугольника получены зависимости интенсивности люминесценции на длинах волн 473, 512, 570, и 715 нм (рис. $3, b)$. Эти результаты типичны для этого образца. На рис. 3, $a$ приведены спектры люминесценции из разных областей образца. Видно, что по характеру люминесценции образец $\mathrm{ZnSe}-\mathrm{Se}$ можно, как и в случаe $\mathrm{ZnSe}-\mathrm{Ar}$, разделить минимум на две области область 1, прилегающая к поверхности, в которой минимизирована люминесценция экситона и примеснодефектных центров (ПДЦ) в диапазоне до 520 нм, и область 2 внутри образца. Область 1 , как и в случае $\mathrm{ZnSe}-\mathrm{Ar}$, располагается по граням образца и имеет вид полосы, параллельной поверхности шириной 200 мкм. Область 2 характеризуется большой по интенсивности люминесценцией экситона и люминесценцией ПДЦ с максимумом вблизи 500, и 520 нм - полоса 520-540 и длинноволновым хвостом до 650 нм, на котором четко фиксируется максимум вблизи 630 нм (рис. 3, $a$, кривые 3,4$)$. Также достаточно четко проявляется уширение экситонной линии, которое, вероятнее всего, связано с появлением еще одной линии с максимумом вблизи 483 нм. Как и в случае кристаллов $\mathrm{ZnSe}-\mathrm{Ar}$, зону 2 можно условно разделить на две подзоны. Однако в отличие от $\mathrm{ZnSe}-\mathrm{Ar}$ в подзоне 2.1, примыкающей к зоне 1 , интенсивность люминесценции экситона и полосы 500-520 несколько меньше, чем в центральной зоне (подзона 2.2), при этом наблюдается ее медленное нарастание в этом спектральном интервале. В центре кристалла в зоне 2.2 интенсивность люминесценции становится относительно однородной. Зона 1 так же, как и в образцах $\mathrm{ZnSe}-\mathrm{Ar}$, делится на две подзоны. Однако в отличие от образцов $\mathrm{ZnSe}-\mathrm{Ar}$ в подзоне 1.1 $\mathrm{ZnSe}-\mathrm{Se}$ практически отсутствует люминесценция экситона. В ней доминирует люминесценция, сходная с полосой 560 в кристаллах $\mathrm{ZnSe}-\mathrm{Ar}$, и красная люминесценция (рис. $3, a$, кривая 1 , см. вставку, кривая 1 ). Ширина 

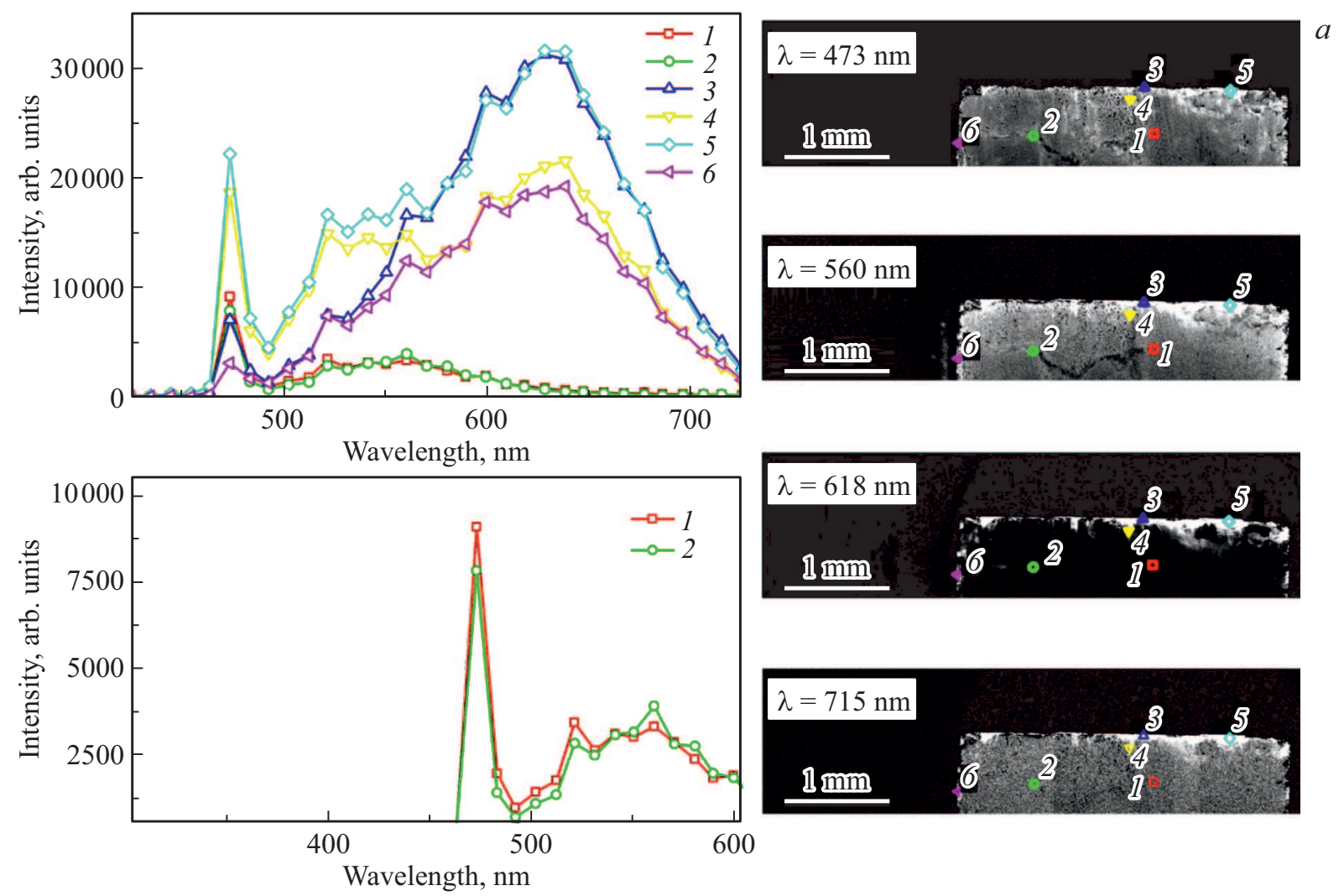

Рис. 4. $a-$ карты люминесценции $\mathrm{ZnSe}-\mathrm{Zn}$ на длинах волн 560 и 715 нм и спектры люминесценции из разных зон кристалла: кривые 1,2 - характеризующие объем кристалла, кривые 3,5,6 - характеризующие приповерхностную область, кривая 4 - из области границы зерна; $b$ - карты люминесценции $\mathrm{ZnSe}-\mathrm{Zn}$ на длине волны 473 нм и зависимости интенсивности люминесценции от расстояния от края кристалла на длинах волн 473, 512, 560 и 715 нм.

подзоны $1.1 \sim 120$ мкм. За ней идет зона 1.2 , в которой минимальна люминесценция во всем регистрируемом в данной работе спектральном диапазоне (ОНИЛ). Ширина ОНИЛ составляет 60-80 мкм (рис. 3, $a$, кривая 2, см. вставку, кривая 2). Размеры зерен в $\mathrm{ZnSe}-\mathrm{Se}$ также увеличились, однако в отличие от $\mathrm{ZnSe}-\mathrm{Ar}$ ситуация с люминесценцией границ зерен усложнилась. Скорее всего, границы зерен, которые пересекают область 1 образца, имеют слабую интенсивность люминесценции практически во всем регистрируемом в данной работе спектральном интервале. Исключение - часть границы зерна в области 1, в которой наблюдается интенсивная красная люминесценция (рис. 3, $a, b$ ). Однако, похоже, что границы зерен, не контактирующие с областью 1 , имеют обычные для границ зерен люминесцентные характеристики - слабую интенсивность люминесценции в середине границы зерна и более сильную - в области вокруг нее. Приповерхностная зона так же, как и в $\mathrm{ZnSe}-\mathrm{Ar}$, характеризуется малой интенсивностью люминесценции во всем спектральном диапазоне.

Таким образом, зависимость интенсивности люминесценции от расстояния от поверхности кристалла для экситона представляется следующим образом. В зоне $1-$ это плато очень слабой интенсивности (скорее всего, экситонная люминесценция в этой части кристалла отсутствует). В конце зоны 2.1 - быстрый рост интенсивности люминесценции, замедляющийся на глубине $\sim 250$ мкм, с выходом на плато на расстоянии $\sim 1000$ мкм от поверхности кристалла. Сходная зависимость для интенсивности люминесценции в спектральном диапазоне 492-540 нм (рис. 3, $b$ ). Для интенсивности люминесценции в спектральном диапазоне 560 нм ситуация сложнее. В подзоне 1.1 наблюдается характерная область ОПИЛ шириной $\sim 60$ мкм. В остальном объеме пространственное распределение интенсивности люминесценции близко к аналогичной зависимости для экситонов и люминесценции в диапазоне 492-540 нм, но с несколько меньшей, чем в случае экситонной линии и полосы 500-520 в зоне 1.2, скоростью нарастания люминесценции в этом спектральном диапазоне. Возможно, что, как и в случае $\mathrm{ZnSe}-\mathrm{Ar}$, пространственная зависимость интенсивности люминесценции в этом диапазоне в области 2 кристалла определяется не полосой 560 , а длинноволновым хвостом полосы 500-520. Зависимость интенсивности красной люминесценции в зоне 1 сходна с аналогичной зависимостью линии 560 - ОПИЛ в зоне 1.1. Далее следует резкий рост интенсивности, которая на расстоянии 250 мкм от поверхности (там же, где происходит перегиб в скорости нарастания экситонной и других линий) выходит на плато. На рис. 4 

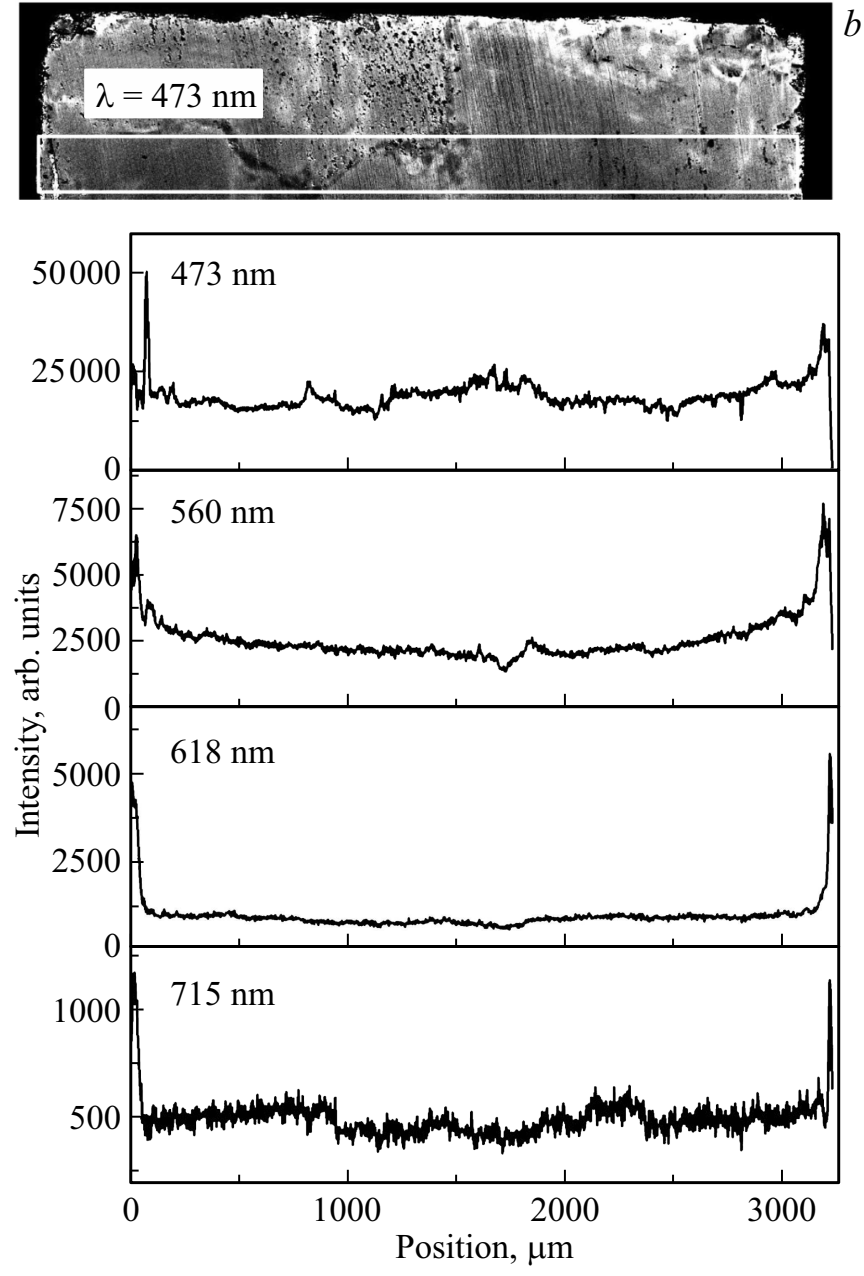

Рис. 4 (продолжение).

приведены плоские карты люминесценции отожженного в парах цинка CVD-ZnSe $(\mathrm{ZnSe}-\mathrm{Zn})$, снятые на длинах волн 473, 540, 618 и 715 нм на расстоянии 100 мкм от поверхности кристалла.

В области выделенного на плоской карте прямоугольника получены зависимости интенсивности люминесценции на длинах волн 473, 540, 618 и 715 нм (рис. 4, b). Эти результаты типичны для этого образца. На рис. 4, a приведены также спектры из разных зон кристалла. В отличие от кристаллов $\mathrm{ZnSe}-\mathrm{Ar}$ и $\mathrm{ZnSe}-\mathrm{Se}$ в этом материале отсутствует характерная зона 1 , наблюдается интенсивная люминесценция экситона и ПДЦ с максимумами 520, 540, 560 нм, похожая на люминесценцию ПДЦ 520-560 в $\mathrm{ZnSe}-\mathrm{Ar}$ (рис. 4, a, кривые 1,2). Образец в макроскопическом плане однороден (рис. 4). Однако зона у поверхности кристалла в отличие от кристаллов $\mathrm{ZnSe}-\mathrm{Ar}$ и $\mathrm{ZnSe}-\mathrm{Se}$ характеризуется большой интенсивностью экситонной и примесно-дефектной люминесценции (рис. 4, a, кривые 3, 4, 6). Спектры ПДЦ широкие и занимают часто весь спектральный интервал. В них регистрируются полосы, похожие на полосу 520-560, и полоса с максимумом вблизи $630 \mathrm{Hм}$ (рис. 4, $a$, кривые 3,4-6). Эта зона не похожа на ОПИЛ. Она пространственно неоднородна (рис. 4, a) и скорее выглядит как декорирование крупных дефектов у поверхности и, в ряде случаев, распространяется в объем кристалла на 50-100 мкм. В случаях, когда граница зерен достигает этой зоны, ее люминесценция на глубине 200-300 мкм имеет вид, характерный для поверхностного слоя (рис. 4, $a$, кривая 5). В объеме же образца границы зерен окружены широкими (порядка $\sim 50$ мкм) областями с пониженной интенсивностью люминесценции во всем спектральном диапазоне (включая красную люминесценцию).

\section{4. Обсуждение результатов}

Как следует из экспериментальных данных, отжиг $\mathrm{ZnSe}$ в аргоне и селене приводит к существенной пространственной неоднородности люминесцентных характеристик образцов. В зоне 1 наблюдаются полосы, параллельные поверхности образца, шириной сотни микрометров, с разной интенсивностью люминесценции в том или ином спектральном диапазоне. Похожая неоднородность люминесцентных характеристик наблюдалась в кристаллах $\mathrm{ZnSe}$, легированного железом и хромом [16,17]. В работе [18] было показано, что такая неоднородность характерна для полупроводников, в которых есть градиенты концентрации ПДЦ. Обычно такие градиенты образуются в результате диффузии примесей или собственных точечных дефектов. Скорее всего, неоднородности в отожженных в аргоне и селене кристаллах $\mathrm{ZnSe}$ также формируются в результате диффузии точечных дефектов. В пользу этого говорит и то, что границы полос искривляются в случае их пересечения границами зерен. Известно, что диффузия точечных дефектов по границам зерен протекает быстpee. В случаe $\mathrm{ZnSe}$, отожженного в парах цинка, подобной неоднородности не наблюдалось. В этих образцах регистрируется большая интенсивность люминесценции в областях, примыкающих к поверхности кристалла, включая примесные атмосферы вокруг границ зерен. Эта неоднородность не имеет вид ОПИЛ, а скорее похожа на декорирование крупномасштабных дефектов структуры. В работе [19] сообщалось об исследовании люминесцентных характеристик образцов $\mathrm{CVD}-\mathrm{ZnSe}$, подвергнутых газостатической обработке в аргоне: $T=1200^{\circ} \mathrm{C}$, $P=90$ МПа, в течение 53 ч. Люминесценция этих образцов была в макроскопическом плане однородна. Спектр люминесценции был близок к спектру исходных поликристаллов с несколько большей интенсивностью люминесценции ПДЦ.

Эти результаты позволяют предполагать, что при отжиге $\mathrm{ZnSe}$ в аргоне и селене происходит преимущественное испарение цинка с поверхности кристалла. В работе [20] было показано, что при температуре отжига $>900^{\circ} \mathrm{C}$, в паровой фазе преобладают атомы цинка. В результате у поверхности образуются зоны с 
повышенной концентрацией вакансий цинка, пониженной концентрацией межузельных атомов цинка и избытком селена. В случае отжига в селене величина этих эффектов должна быть больше, чем в случае отжига в аргоне. В результате в этих кристаллах за счет диффузии из объема будут образовываться диффузионные профили концентраций собственных точечных дефектов. В случае отжига в парах цинка процесс испарения цинка с поверхности затруднен, происходит насыщение приповерхностной области межузельным цинком, который декорирует поверхностные дефекты и границы зерен.

Кроме того, в процессе отжига во всех атмосферах происходит укрупнение зерен $\mathrm{ZnSe}$ и растворение регистрируемых в исходном ZnSe областей с повышенной концентрацией ПДЦ. Также в процессе отжига остаточные примеси и собственные точечные дефекты могут диффундировать к стокам в виде границ зерен и поверхности кристалла, а также их преципитация. Таким образом, во время отжига образцов $\mathrm{ZnSe}$ в них происходит целый ряд процессов, которые могут существенно влиять как на примесно-дефектный состав кристаллов, так и на пространственное распределение ПДЦ в них. Все эти процессы приводят к регистрируемой экспериментально сложной картине пространственного распределения люминесцентных характеристик в кристаллах, подвергаемых высокотемпературному отжигу. В случае газостатической обработки процессы испарения и внедрения в кристалл собственных точечных дефектов затруднены и концентрация собственных точечных дефектов в приповерхностной зоне относительно стабильна. В таких образцах происходят только „внутренние“ процессы укрупнение зерен, преципитация и т.д. Как показано в работе [19], в результате газостатической обработки не происходит качественных изменений в примеснодефектном составе и пространственном распределении люминесценции (за исключением укрупнения зерен). Это позволяет утверждать, что за наблюдаемые в данной работе эффекты ответственны именно процессы испарения и внедрения собственных точечных дефектов.

По-видимому, наблюдаемые в $\mathrm{ZnSe}-\mathrm{Ar}$ и $\mathrm{ZnSe}-\mathrm{Se}$ полосы с повышенной и пониженной люминесценцией (ОПИЛ и ОНИЛ) связаны с образующимися в них профилями концентраций собственных точечных дефектов - вакансий и межузельных атомов цинка и селена. Эти точечные собственные дефекты могут образовывать различные ПДЦ как между собой, так и с остаточными примесями. Пространственное распределение этих ПДЦ будет определяться профилями концентраций, образующих их собственные точечные дефекты. Рекомбинация неравновесных носителей через эти ПДЦ и приводит к образованию наблюдаемых полос. В случае если рекомбинация является излучательной в спектральном интервале, регистрируемом в данной работе, то будут наблюдаться ОПИЛ. В случае же безызлучательной рекомбинации или люминесценции в диапазонах вне 0.5-0.72 мкм будут регистрироваться ОНИЛ. В случае $\mathrm{ZnSe}-\mathrm{Zn}$ внедренный из атмосферы цинк, скорее всего, активно захватывается дефектами структуры в приповерхностном слое и прилегающими к нему границами зерен. Взаимодействие Zn с остаточными примесями приводит к образованию большого количества ПДЦ, связанных с крупномасштабными дефектами структуры. Специфика данной поверхности привела к тому, что эти ПДЦ имеют высокую интенсивность люминесценции в исследуемом диапазоне спектра. Полученная информация о пространственном распределении люминесцентных характеристик позволяет сделать некоторые более конкретные предположения о процессах, происходящих при отжигах и природе ПДЦ в отожженных кристаллах. В кристалле $\mathrm{ZnSe}-\mathrm{Ar}$ область 1 характеризуется малой интенсивностью люминесценции в регистрируемом в данной работе диапазоне. Вероятнее всего, рекомбинация носителей в этой зоне происходит через ПДЦ либо безызлучательно, либо с излучением вне диапазона 0.44-0.75 мкм. Учитывая то, что в этой зоне должна быть высокая концентрация $V_{\mathrm{Zn}}$, можно предположить, что они входят в состав этих ПДЦ (ПДЦ $\left.-V_{Z n}\right)$.

Отметим, что в работе [19] наблюдаемая в выращенном аналогичном режиме CVD-ZnSe линия в диапазоне 1300-1400 нм связывалась с $V_{Z n}$. По-видимому, концентрация $V_{\mathrm{Zn}}$ и, соответственно, ПДЦ- $V_{\mathrm{Zn}}$ быстро падают с удалением от поверхности образца и к концу зоны 1 их вклад в рекомбинацию носителей становится незначительным. В этой же зоне формируется ОПИЛ с ПДЦ, люминесцирующие в диапазоне 560 нм. Учитывая то, что эта область $\mathrm{ZnSe}-\mathrm{Ar}$ содержит высокую концентрацию избыточного селена, логично предположить, что в состав этих ПДЦ входит Se (ПДЦ-Se). Концентрация избыточного селена (и, соответственно, ПДЦ-Se) так же уменьшается при удалении от поверхности. В том случае, если спад концентрации, ПДЦ-Se менее быстрый, чем ПДЦ- $V_{\mathrm{Zn}}$, то возникают условия для образования ОПИЛ [18]. При дальнейшем увеличении расстояния от поверхности роль ПДЦ-Se падает. Наблюдаемое же увеличение интенсивности люминесценции в этом диапазоне, скорее всего, связано с длинноволновым хвостом полосы 520-540. С уменьшением влияния ПДЦ- $V_{\mathrm{Zn}}$ и ПДЦ-Se на рекомбинацию носителей возрастает вероятность рекомбинации через экситоны. Соответственно увеличивается интенсивность экситонной люминесценции. Она достигает максимума на расстоянии $\sim 550$ мкм от поверхности. Затем начинается ее спад, который на расстоянии 750 мкм выходит на плато. Объяснить это можно, предположив, что в процессе отжига в $\mathrm{ZnSe}-\mathrm{Ar}$ образуется большое количество ПДЦ, включающих в себя $V_{\mathrm{Se}}$. Рекомбинация через эти ПДЦ (ПДЦ- $\left.V_{\mathrm{Se}}\right)$ происходит либо безызлучательно, либо с излучением вне регистрируемого спектрального диапазона. Отметим, что в работе [21] линии 830 и 960 нм были связаны с $V_{\mathrm{Se}}$. Концентрация этих ПДЦ спадает к поверхности за счет аннигиляции $V_{\mathrm{Se}}$ избыточным селеном, поступающим из обогащенного им поверхностного слоя. В зоне 1 влияние этих ПДЦ невелико, но при увеличении расстояния от поверхности снижается 
роль ПДЦ $-V_{\mathrm{Zn}}$ и ПДЦ-Se и на расстояниях больше 500 мкм влияние ПДЦ- $V_{\mathrm{Se}}$ становится существенным. На расстоянии 750 мкм от поверхности фактор влияния потока избыточного селена становится ничтожным и концентрация ПДЦ $-V_{\mathrm{Se}}$ и его влияние на экситонную люминесценцию стабилизируется. Ситуация с пространственной зависимостью интенсивности люминесценции полосы $520-540$ нм в основном может быть объяснена так же, как и зависимость экситонной люминесценции, в случае если ПДЦ, обеспечивающие люминесценцию этой полосы, распределены по образцу равномерно. Однако в пространственных зависимостях интенсивности люминесценции экситонной линии и полосы 520-540 нм есть одно различие - в зоне 1 интенсивность экситонной люминесценции растет, а полосы 520-540 нм скорее всего просто отсутствует. При дальнейшем удалении от поверхности эти зависимости близки. Эту разницу можно объяснить предположением, что в состав ПДЦ, ответственных за полосу 520-540 нм, входит межузельный цинк $\left(П Д Ц-\mathrm{Zn}_{i}\right)$. В этом случае, в связи с тем что в зоне 1 концентрация межузельного цинка $\mathrm{Zn}_{i}$ мала, люминесценция в этой зоне полосы $520-540$ нм может быть подавлена. При дальнейшем удалении от поверхности концентрация $\mathrm{Zn}_{i}$ и, соответственно, ПДЦ $-\mathrm{Zn}_{i}$ стабилизируются и пространственная зависимость интенсивности люминесценции полосы $520-540$ нм совпадает с аналогичной зависимостью экситонной люминесценции. Сходными процессами (с учетом существенно большей концентрации избыточного селена и вакансий цинка) может быть объяснена и ситуация в $\mathrm{ZnSe}-\mathrm{Se}$. Рекомбинация через ПДЦ- $V_{\mathrm{Se}}$ за счет высокой концентрации этих центров практически полностью подавляет экситонную люминесценцию и люминесценцию полосы $500-520$ нм в зоне 1. Существенно больший избыток селена разрушает комплексы ПДЦ- $V_{\mathrm{Se}}$ во всем объеме кристалла. В результате спада интенсивности экситонной люминесценции и люминесценции полосы $500-520$ нм при большом удалении от поверхности не наблюдается. Так как ОПИЛ на длине волны 560 связывается в $\mathrm{ZnSe}-\mathrm{Ar}$ с диффузией избыточного селена с поверхности и образованием ПДЦ-Se, то естественно, что и в кристалле $\mathrm{ZnSe}-\mathrm{Se}$ появление ОПИЛ на длине волны 560 нм связывается с аналогичными причинами. Полоса $520-540$ нм может трансформироваться в полосу 500-520 нм в связи с образованием новых ПДЦ и перестройкой ПДЦ $-\mathrm{Zn}_{i}$. Эти процессы могут быть связаны как с избытком селена во всем кристалле, так и с освобождением различных точечных дефектов после развала ПДЦ $-V_{\mathrm{Se}}$. Отметим, что в сходных кристаллах $\mathrm{CVD}-\mathrm{ZnSe}$ в областях кристаллов с избытком селена в работе [17] наблюдались близкие полосе $500-520$ нм спектры люминесценции. В статье [22] линия вблизи 500 нм так же связывалась с избытком селена.

Природа ПДЦ, образующих красные линии, неясна. В работе [23] линии в этом диапазоне ассоциировались с люминесценцией, изолированной $V_{\mathrm{Zn}}$. В пользу этого говорит то, что их люминесценция регистрируется в зоне $1 \mathrm{ZnSe}-\mathrm{Ar}$ и $\mathrm{ZnSe}-\mathrm{Se}$. Однако на основе этой гипотезы сложно объяснить возрастание интенсивности люминесценции этих линий при удалении от поверхности кристалла. Интенсивность их люминесценции мала, что затрудняет их исследование, не исключено, что эта группа линий образована ПДЦ разной природы.

$\mathrm{B} \mathrm{ZnSe}-\mathrm{Zn}$, как и в случае газостатической обработки, не происходит столь существенных изменений в примесно-дефектном составе и однородности кристаллов. Люминесценция основной части этого кристалла достаточно однородна и близка к люминесценции области $2 \mathrm{ZnSe}-\mathrm{Ar}$. Это позволяет предполагать, что природа ПДЦ, образующих полосы 520-540, одинакова. Тот факт, что интенсивность этой полосы возрастает в приповерхностной зоне, где должна быть велика концентрация межузельного цинка, подтверждает предположение о том, что в состав ПДЦ- $\mathrm{Zn}_{i}$ действительно входит межузельный цинк.

Неясна природа полосы 630, четко регистрируемой в приповерхностной зоне $\mathrm{ZnSe}-\mathrm{Zn}$. С учетом того что она наиболее интенсивна в зоне, где предполагается высокая избыточная концентрация цинка, логично связать ее с этим дефектом. Однако похожая линия наблюдается на хвосте полосы $500-520$ в $\mathrm{ZnSe}-\mathrm{Se}$. Безусловно, предлагаемая выше картина примесно-дефектного состава и его распределения в кристаллах после термообработок носит только предварительный характер. Указанные выше процессы, которые могут происходить при отжигах, приводят к наблюдаемой сложной картине в пространственном распределении люминесцентных характеристик в объеме кристаллов $\mathrm{ZnSe}$, границ зерен и дефектов структуры. Для того чтобы разобраться в ней, требуются дополнительные эксперименты по изотермическим отжигам и газостатической обработке при сходных температурах, привлечение других методов (в частности методов анализа химического состава поверхности).

\section{5. Заключение}

В заключение сформулируем кратко основные результаты и выводы из проделанной работы.

1. Отжиг $\mathrm{ZnSe}$ при $1000^{\circ} \mathrm{C}$ в газовых атмосферах при невысоких давлениях газа приводит к существенным изменениям в примесно-дефектном составе и существенной неоднородности пространственного распределения люминесцентных характеристик в диапазоне 0.45-0.72 мкм кристаллов, в особенности в приповерхностной зоне шириной в несколько сотен мкм.

2. В $\mathrm{ZnSe}-\mathrm{Ar}$ и $\mathrm{ZnSe}-\mathrm{Se}$ зарегистрированы ОПИЛ и ОНИЛ, что свидетельствует о диффузионном характере процессов, происходящих при отжиге в этих кристаллах.

3. На основании пространственного распределения люминесцентных характеристик сделаны предположения о составе образующихся в процессе отжига ПДЦ. 


\section{Финансирование работы}

Работа выполнена с использованием оборудования центра коллективного пользования „Аналитический центр ФГБУ ФИЦ ИОФ РАН“ при частичной финансовой поддержке гранта РФФИ № 18-29-20048, в части, связанной с разработкой технологии и изготовления образцов, работа поддержана грантом РНФ № 19-13-00205.

\section{Конфликт интересов}

Авторы заявляют, что у них нет конфликта интересов.

\section{Список литературы}

[1] S.B. Mirov, V.V. Fedorov, D. Martyshkin, I.S. Moskalev, M. Mirov, S. Vasilyev. IEEE J. Select. Top. Quant. Electron., 21 (1), (2015)

[2] S. Vasilyev, I. Moskalev, M. Mirov, V. Smolski, D. Martyshkin, V. Fedorov, S. Mirov, V. Gapontsev. Proc. of SPIE, Ultrafast Bandgap Photonics II (Anaheim, California, US, 2017) v. 10193.

[3] S.V. Kurashkin, O.V. Martynova, D.V. Savin, E.M. Gavrishchuk, S.S. Balabanov, V.B. Ikonnikov, V.V. Sharkov. Phys. Lett., 16, 075801 (2019).

[4] A.A. Gladilin, E.S. Gulyamova, V.P. Danilov, N.N. Il'ichev, V.P. Kalinushkin, I.N. Odin, P.P. Pashinin, R.R. Rezvanov, A.V. Sidorin, M.I. Studenikin, V.A. Chapnin, M.V. Chukichev. Quant. Electron., 46 (6), 545 (2016).

[5] N.N. Il'ichev, A.A. Gladilin, E.S. Gulyamova, V.P. Kalinushkin, S.A. Mironov, A.V. Sidorin, P.P. Pashinin, V.V. Tumorin, E.M. Gavrishchuk, D.V. Savin, S.A. Rodin, V.B. Ikonnikov, M.V. Chukichev. Quant. Electron., 50, (8) 730, (2020).

[6] O. Gafarov, A. Martinez, V. Fedorov, S. Mirov. Optical Mater. Express, 7 (1), 25 (2017).

[7] S.A. Rodin, E.M. Gavrishchuk, V.B. Ikonnikov, D.V. Savin. Inorg. Mater., 54 (1), 21 (2018).

[8] N.A. Timofeeva, E.M. Gavrishchuk, D.V. Savin, S.A. Rodin, S.V. Kurashkin, V.B. Ikonnikov, T.S. Tomilova. Inorg. Mater., 55, 1274 (2019).

[9] D.D. Nedeoglo, A.V. Simashkevich. Electric and Luminescent Properties of Zinc Selenide (Kishinev, Shtiintsa, 1984).

[10] Yu.F. Vaksman Yu.A. Nitsuk, V.V. Yatsun, A.S. Nasibov, P.V. Shapkin. Semiconductors, 45, 1129, (2011).

[11] G. Colibaba, M. Caraman, I. Evtodiev, S. Evtodiev, E. Goncearenco, D. Nedeoglo, N. Nedeoglo. J. Luminesc., 145, 237 (2014).

[12] I. Abbasov, M. Musayev, J. Huseynov, M. Kostyrko, S. Babayev, G. Eyyubov, S. Aliyeva. Ukr. J. Phys. Opt., 21 (2), 103 (2020).

[13] В.П. Калинушкин, О.В. Уваров. ЖТФ, 86 (12), 119 (2016).

[14] V.P. Kalinushkin, O.V. Uvarov, A.A. Gladilin, J. Electron. Mater., 47, 5087 (2018).

[15] Н.К. Морозова, Е.М. Гаврищук, И.А. Каретников, О.Р. Голованова, В.С. Зимогорский, В.Г. Галстян. ЖПС, 63 (5), 731 (1996).

[16] A. Gladilin, O. Uvarov, S. Mironov, N. Timofeeva, E. Gavrischuk, V. Kalinushkin. Acta Phys. Polon. A, 136 (4), 637, (2019).
[17] S. Balabanov, E.M. Gavrishchuk, A.A. Gladilin,V.B. Ikonnikov, N.N. Il'ichev, V.P. Kalinushkin, S.A. Mironov, D.V. Savin, M.I. Studenikin, N.A. Timofeeva, O.V. Uvarov, V.A. Chapnin. Inorg. Mater., 55 (5), 423, (2019).

[18] V.P. Kalinushkin, O.V. Uvarov, S.A. Mironov, K. Nartov, N.N. Il'ichev, M.I. Studenikin, E.M. Gavrischuk, N.A. Timofeeva, S.A. Rodin, A.A. Gladilin. J. Luminesc., 231, 117795 (2021).

[19] Е.М. Гаврищук, А.А. Гладилин, В.П. Данилов, В.Б. Иконников, Н.Н. Ильичев, В.П. Калинушкин, А.В. Рябова, М.И. Студеникин, Н.А. Тимофеева, О.В. Уваров, В.А. Чапнин. Неорг. матер., 52 (11), 1180 (2016).

[20] С.А. Медведев, В.Н. Мартынов, С.П. Кобелева, Н.Д. Ахмед-Заде. Электр. техн., сер. Материалы, вып. 11, 87 (1980).

[21] Н.К. Морозова, И.А. Каретников, В.В. Блинов, Е.М. Гаврищук. ФТП, 35 (5), 534 (2001).

[22] S. Kishida, K. Matsuura, H. Mori, T. Yanagawa, I. Tsurumi, C. Hamaguchi. Phys. Status Solidi A, 106, 283 (1988).

[23] K.M. Lee, Le Si Dang, G.D. Watkins. Sol. St. Commun., 35 (7), 527, (1980).

Редактор А.Н. Смирнов

\section{Effect of annealing atmosphere on the luminescence characteristics of CVD-ZnSe}

V.P. Kalinushkin ${ }^{1}$, A.A. Gladilin ${ }^{1}$, O.V. Uvarov ${ }^{1}$, S.A. Mironov ${ }^{1 *}$, V.A. Chapnin ${ }^{1}$, M.I. Studenikin ${ }^{1}$, N.N. Il'ichev ${ }^{1}$, E.M. Gavrishchuk ${ }^{2}$, S.A. Rodin ${ }^{2}$, N.A. Timofeeva ${ }^{2}$

${ }^{1}$ Prokhorov General Physics Institute of the Russian Academy of Sciences, 119991 Moscow, Russia

${ }^{2}$ Institute of Chemistry of High-Purity Substances named after G.G. Devyatykh of the Russian Academy of Sciences, 603951 Nizhny Novgorod, Russia

Abstract The influence of the atmosphere of CVD-ZnSe annealing carried out in modes close to the procedure of their doping with iron on the luminescent characteristics of these crystals is investigated. It was found that annealing in the atmosphere of argon and selenium leads to a qualitative change in the impuritydefect composition and to a complex spatial distribution of the luminescent characteristics of CVD-ZnSe, especially in the crystal region at a distance of up to 400 microns from the surface. In the case of annealing in zinc, the luminescent characteristics are more uniform, with the exception of the near-surface zone with a width of about 100 microns, which has a high luminescence intensity in the entire spectral range under study $(0.44-0.72$ microns $)$. The obtained results are interpreted on the basis of the assumption about the evaporation of zinc during annealing in argon and selenium. Based on the analysis of the spatial distribution of luminescence, assumptions are made about the nature of the observed impurity-defect centers. 